\title{
KNOWLEDGE, ATTITUDE, AND PRACTICES OF NON-COMMUNICABLE DISEASES: COMPARISON BETWEEN ORANG ASLI AND MALAY FROM RURAL AREA IN NEGERI SEMBILAN, MALAYSIA: A COMPARATIVE STUDY
}

\author{
Muslimah Ithnin ${ }^{1}$, Norsham Juliana ${ }^{2}$, Nadeeya 'Ayn Umaisara Mohamad Nor ${ }^{3}$, Nadia Mohd Effendy ${ }^{4}$ and \\ Mohd Dzulkhairi Mohd Rani ${ }^{3}$ \\ ${ }^{1}$ Faculty of Medicine and Health Sciences, Universiti Sains Islam Malaysia, Kuala Lumpur, Malaysia. \\ ${ }^{2}$ Department of Medical Science I, Faculty of Medicine and Health Sciences, Universiti Sains Islam Malaysia, Kuala \\ Lumpur, Malaysia \\ ${ }^{3}$ Department of Primary Care, Faculty of Medicine and Health Sciences, Universiti Sains Islam Malaysia, Kuala Lumpur, \\ Malaysia \\ ${ }^{4}$ Department of Medical Science II, Faculty of Medicine and Health Sciences, Universiti Sains Islam Malaysia, Kuala \\ Lumpur, Malaysia
}

Corresponding author: Mohd Dzulkhairi Mohd Rani

Email: drdzulkhairi@usim.edu.my

\begin{abstract}
The study evaluates the prevalence, knowledge, attitude, and practices of non-communicable diseases (NCDs) among adult Orang Asli and Malay ethnicity in Negeri Sembilan, Malaysia. This cross-sectional study involving 634 respondents aged 18 years and above of Orang Asli (51.3\%) and Malays (48.7\%) from the rural villages. Structured interview questionnaire for disease history and KAP level conducted. Weight, height, waist circumference, blood pressure, and blood glucose levels then measured. Prevalence of NCDs was higher among Malays compared to Orang Asli with hypertension (35.0\% vs $14.8 \%$ ), hypercholesterolemia (31.1\% vs $5.2 \%)$, and diabetes mellitus (16.2\% vs $4.3 \%)$, respectively. Malays also had a higher percentage of being abdominal obese (70.6\% vs 59.7\%) and increased blood pressure (54.4\% vs 29.8\%). Multivariate analysis indicates hypercholesterolemia [OR=6.035 (95\% Cl: $3.150,11.561)]$, abdominal obesity [aOR $=1.807(95 \% \mathrm{Cl}: 1.065,3.067)$ ], and increased in blood pressure [aOR= 2.359 (95\% 1 : 1.619,3.437)] have a significant relation with Malay ethnicity. For Orang Asli, 51.7\% had poor knowledge, $72.3 \%$ had a good attitude, and $16.0 \%$ had a good practice. Knowledge and attitude scores were significantly less among Orang Asli with no significant difference for practice compared to the Malays. The prevalence of NCDs among the Malays is alarmingly high, with an increasing trend among Orang Asli, which needs immediate attention. The NCDs and obesity were significant among Malays but also showed a worrying trend in the Orang Asli as the good practice on a healthy life-style was low in both ethnicities. Thus, proper education and promotion regarding NCDs needed for diseases screening and prevention.
\end{abstract}

Keywords: Knowledge, Attitude, Practices, Non-Communicable Disease, Orang Asli, Malay.

\section{INTRODUCTION}

Non-communicable diseases (NCDs) or chronic diseases are the significant and growing public health problems affecting all countries, including Malaysia. Report by the World Health Organization (WHO) in 2018 showed that from fourth reported death in Malaysia, three of them were due to non-communicable diseases ${ }^{1}$. Cardiovascular diseases, including heart attacks and stroke, account for most NCD deaths, followed by cancers, chronic respiratory diseases, and diabetes. Unhealthy lifestyle factors and health-related behaviours such as smoking, alcohol consumption, physical activity, and dietary habits can affect a person's health and often results in a higher risk of these chronic diseases. The four major types of NCDs also share this same lifestyle-related risk factors ${ }^{2}$.

In the National Health and Morbidity Surveys (NHMS) 2015 report, the national prevalence showed an increasing trend for all NCD risk factors in Malaysia. Based on the report, there was a variation between states. Negeri Sembilan lies on the western coast of Peninsular Malaysia with Selangor on the north, Pahang in the east, and Melaka and Johor to the south. Negeri Sembilan comprised of seven districts and is known to have a heterogeneous population in terms of ethnic groups and rural-urban distribution. Comparing among states, Negeri Sembilan had among the highest prevalence of diabetes, hypertension, and obesity, with a percentage of $10.5 \%, 16.1 \%$, and $23.5 \%$, respectively. Furthermore, the prevalence of NCDs slightly higher in the urban areas compared to rural, but the difference was not statistically significant ${ }^{3}$.

An increase in the risk factors of NCDs includes smoking, inactive life (sedentary or less physical activity), obesity, and poor dietary habits observed with socio-economic development and urbanization in rural Malaysia. This transition affected the morbidity and mortality trends not only in major ethnic but also in the minority ethics of indigenous people that also known as Orang Asli ethnic. Previous investigations mainly reported infectious diseases among Orang $\mathrm{Asli}^{4}$. However, 
due to the epidemiological transition marked in rural Malaysia, the trend of the disease is now shifted from communicable to non-communicable diseases with no exception among the Orang Asli, particularly those staying in the vicinity of townships, and the out-skirt of existing rural villages $^{5-7}$.

Since NCDs mainly attributed to the unhealthy lifestyle of the individual, prevention of the diseases can be started earlier by having adequate knowledge of the conditions and adopting healthy lifestyle practices. This is primarily crucial as the illnesses might be under diagnosed and lead to several complications of the significant organ, including the brain, eyes, and kidney ${ }^{8,9}$. Even though numbers of studies ${ }^{10-12}$ reported on KAP level of chronic diseases in the general population, little is known about the knowledge towards NCDs among Orang Asli. To the best of our knowledge, only one study conducted looking at the knowledge of diabetes among the Orang Asli by Ahmad et al. in $2013^{13}$, with none of the reported research looking at the KAP towards NCDs conducted among the Malays and Orang Asli populations who are living nearby. By knowing the level of knowledge, attitude and practices of the community who are at risk will allow effective education and prevention programs targeting the benefits of healthy lifestyle behaviour which have the most significant impact on NCD prevention.

Therefore, the current study aimed to investigate and compared the prevalence of major NCDs and NCDs risk among the Orang Asli and the Malay populations in rural Negeri Sembilan, Malaysia. Their knowledge, attitude and practices (KAP) towards NCDs also determined and compared.

\section{METHODS}

\section{Study Design}

A cross-sectional study was conducted from November 2017 to December 2018 among Malay and Orang Asli population in rural Negeri Sembilan of Peninsular Malaysia.

Ethical approval obtained from the Ethics Committee of Human Research Ethics Committee, Universiti Sains Islam Malaysia, and the Medical Research and Ethics Committee, Ministry of Health, Malaysia. The purpose and procedures of the study explained to the authorities of the Department of Orang Asli Development (JAKOA), Malaysia, and the Village Community Management Council (MPKK) for Malay villages and the head (Tok Batin) of each village for Orang Asli Village. Written informed consent obtained from all individual respondents included in the study. Procedures were carried out following the Declaration of Helsinki by the World Health Organization in $2001^{14}$.

\section{Study Population}

The minimum sample size required for this study calculated according to the formula provided by Lwanga \& Lemeshow ${ }^{15}$.

$$
n=Z^{2}{ }_{1-\alpha / 2}\left[P_{1}\left(1-P_{1}\right)+P_{2}\left(1-P_{2}\right)\right] / d^{2}
$$

At a $5 \%$ level of significance and a $95 \%$ confidence level, the minimum number of respondents required for the study was estimated at 554 (277 participants from each population), using the prevalence of hypertension among adult Negeri Sembilan populations about $23.5 \%$ as previously reported by Institute of Public Health Malaysia in $2015^{3}$.

Respondents recruited from the community of Malay and Orang Asli in the rural area. The two chosen districts in Negeri Sembilan state were Jelebu and Kuala Pilah. The main sub-tribe that existed here is the Temuan, which belongs to the Proto-Malay tribe group.

The selection of villages conducted using the systematic sampling method. By using this method, a systematic sample is obtained by selecting a random start at the beginning of the list of the villages provided by the authority. The used of this method allow the same precision as a simple random sample ${ }^{16}$. Orang Asli villages and nearby comparable Malay villages identified from both districts as a sampling location.

The Orang Asli villages were categories as rural as it is located near to Malay villages. They also have a good accessibility to such amenities, including piped water, electricity supply, and roads that connect their villages with other surrounding areas. Additional to that they also have a land development project and a sustainable economic source. The set of villages selected in this study were in common in term of infrastructure and economic set-up. The selection of each participant was performed using the purposive and snowballing sampling method based on the defined inclusion and exclusion criteria.

The inclusion criteria were individuals aged between 18 years old and above who provided informed consent. They shall be the ethnicity of Malay and Orang Asli. Anyone with mental or physical disabilities or those who pregnant excluded. Individuals who did not understand the Malay language also excluded since the survey was conducted in Malay.

\section{Structured Questionnaire}

A structured questionnaire was written in English and translated into the Malay language, which is the national language of Malaysia (Bahasa Malaysia). For Orang Asli populations, Bahasa Malaysia is the common second language and the primary language used by villagers to communicate with outsiders. In all locations, the 
Orang Asli villagers have a good command of the national language. Cronbach's alpha test used to assess the internal consistency of the questionnaire. The questionnaire piloted among 30 respondents who had a similar profile of the target population. For the Malay community, Cronbach's alpha coefficient values for KAP domains was $0.700,0.765$ and 0.740 , respectively. Whereas for Orang Asli, the Cronbach's alpha coefficient values for KAP domains was $0.961,0.898$ and 0.705 , respectively. Thus, the Cronbach alpha coefficient values of more than 0.700, reflecting the good internal consistency and reliability of the questionnaire ${ }^{17}$.

The participants were interviewed by trained field assistants who recorded the information pertinent to the respondents. The first part on sociodemographic information of the respondents also sections on knowledge, attitude and practice regarding NCDs in the second part and finally, the anthropometric measure in the third part.

The first part of socio-demographic information of the respondents includes gender, age, and educational level. Their smoking status, alcohol drinking status, and physical activity also assessed. The individual considered physically inactive if they did not conduct any aerobic physical activity that requires energy expenditure for minimum of 150 minutes throughout the week $^{18}$. For chronic disease status, presence or absence of chronic diseases based on selfreported information on chronic conditions diagnosed by a medical professional. Respondents were asked, followed by a list of chronic diseases, including hypertension, hypercholesterolemia, and diabetes mellitus, to which the answer is "yes" or "no"19.

The second part of knowledge, attitude, and practices contained questions regarding NCDs adapted from Ithnin et al. in $2018^{12}$. The answer choices were 'yes,' 'no,' and 'not sure' for 27 knowledge questions. The part on attitude regarding NCDs and its prevention used Likertscale type of items: 15 questions on attitude with five scales of 'strongly agree' to 'strongly disagree.' Six questions on practice with the choices of the response of 'frequent,' 'sometimes,' and 'never' for behavioural practice.

After completing the questionnaire, height measured to the nearest $0.1 \mathrm{~cm}$ and weight measured in the upright position to the nearest $0.1 \mathrm{~kg}$ using a portable Seca 769 Electronic Column Scales (Seca, Germany). Body mass index (BMI) was calculated by dividing weight $(\mathrm{kg})$ by height squared $(\mathrm{m} 2)$, based on the revised criteria specific for Asian/Pacific populations. The value of $\mathrm{BMI} \geq 25 \mathrm{~kg} / \mathrm{m}^{2}$ used to define obese ${ }^{20}$. Waist circumference was measured at the end of normal expiration in a horizontal plane, midway between the inferior margin of the ribs and the superior border of the iliac crest ${ }^{21}$. Waist circumference (WC) measurements recorded to the nearest $1 \mathrm{~cm}$ by using a non-stretchable measuring tape. For assessing central abdominal obesity, waist circumference cut off values of $>90 \mathrm{~cm}$ for men and $>80 \mathrm{~cm}$ for women used in this study ${ }^{20}$.

Systolic and diastolic arterial blood pressure measured by using Omron Automated Blood Pressure Monitor HEM-7120 (Omron, Japan). Automated blood pressure can be used to obtain accurate readings as it also provides feasibility and safety ${ }^{22}$. The measured taken when the subject is calm and not sought after meals or after exercise. The reading taken during sitting on the left hand supported at heart level in sitting upright position. It was measured twice, with two minutes apart when the respondent is at rest. Then, the average measurements used as the BP value for individual respondent ${ }^{23}$. Respondents who had a systolic blood pressure of $140 \mathrm{mmHg}$ or more or diastolic blood pressure of $90 \mathrm{mmHg}$ or more were categories in increased blood pressure groups ${ }^{3}$.

Blood glucose measured by Accu Chek Performa Glucose Meter System (Roche, USA). Respondents with fasting blood glucose (FBG) of $6.1 \mathrm{mmol} / \mathrm{L}$ or more (or non-fasting blood glucose of more than $11.1 \mathrm{mmol} / \mathrm{L})$ were categorized as high blood glucose ${ }^{3}$.

\section{Statistical analysis}

Statistical analysis was carried out using the SPSS 23 statistical software package (SPSS Inc., Chicago, IL). Categorical comparison between Malay and Orang Asli conducted using the ChiSquare test and Fisher-Exact test for bivariate analysis.

Independent variables tested by simple logistic regression and included in multivariate analysis to determine the association between ethnicity and major NCDs and its risk factor. Before performing a linear regression analysis, the assumption of multicollinearity between variables was tested based on the variance inflation factor $<10^{24}$. No evidence of multicollinearity found. All variables with a value of $p<0.25$ in the univariate regression analysis included in the multiple logistic regression analysis. The $p<0.25$ test used based on evidence that the threshold $(p<0.05)$ could exclude relevant variables ${ }^{25}$. Then, the preliminary final model obtained. HosmerLemeshow goodness-of-fittest and classification table used to determine the fitness of the model. The results presented with crude and adjusted Odds Ratio (OR), 95\% Confidence Interval $(\mathrm{Cl})$ and $\mathrm{P}$-value. P-value of less than 0.05 considered statistically significant.

For the knowledge, attitude, and practices part, the correct answers converted to $100 \%$, and marks below $50 \%$ were considered poor, $50 \%-74 \%$ was 
deemed to be moderate, and marks $75 \%$ and above were deemed to be good. Histogram with normality curve and Kolmogorov-Smirnov test were used for the normality and homogeneity of variance for knowledge, attitude and practice score. Since the data not normally distributed, the non-parametric Mann-Whitney test was used to determine the predictor of ethnicity variables for NCDs KAP level. P-values of less than 0.05 considered statistically significant for all the tests.

\section{RESULTS}

Six hundred thirty-four participants fulfilled the inclusion and exclusion criteria, which comprised of 325 (51.3\%) Orang Asli and 309 (48.7\%) Malay from rural villages. The demographic characteristics of the participants summarised in Table 1. The mean age for Orang Asli was 39.94 years \pm 13.196 and 54.61 years \pm 16.112 for Malay. The Orang Asli has significantly lower education level compared to Malay, about $32.9 \%$ of the Orang Asli had no formal education, and only $4.0 \%$ of them had received tertiary education.

Table 2 shows the prevalence of hypertension, hypercholesterolemia, and diabetes mellitus among the rural community was $24.6 \%, 17.8 \%$, and $10.1 \%$, respectively. The percentages of Malay with diagnosed NCDs were higher than the Orang Asli with hypertension (35.0\% vs $14.8 \%)$, hypercholesterolemia $(31.1 \%$ vs $5.2 \%)$ and diabetes mellitus (16.2\% vs $4.3 \%)$, respectively. The Malay respondents also had a higher percentage of being abdominal obese $(70.6 \%$ vs $59.7 \%)$, increased blood pressure (54.4\% vs $29.8 \%$ ), and elevated blood glucose $(8.7 \%$ vs $5.5 \%)$ compared to the Orang Asli. For lifestyle NCDs risk behaviour, smoking cigarette status was 31.7\% for Malay and $28.0 \%$ for the Orang Asli. More than half of the respondents were physically inactive (52.1\%), with $53.7 \%$ and $50.5 \%$ among Malays and the Orang Asli, respectively. For Orang Asli, 7.1\% of them consume the alcoholic drink.
Bivariate testing indicates the relation between ethnicity and determinant factors. The results show that there are six variables with significant correlation, namely, hypertension $(\mathrm{P}<0.001)$, hypercholesterolemia $\quad(P<0.001), \quad$ diabetes mellitus $(P<0.001)$, abdominal obesity $(P=0.004)$, increased blood pressure $(P<0.001)$ and alcohol consumption $(\mathrm{P}<0.001)$.

Multivariate test results (Table 3 ) show three variables have a significant influence in Malay ethnicity, namely, hypercholesterolemia with OR=6.035 (95\%Cl: 3.150,11.561), abdominal obesity with $\mathrm{aOR}=1.807(95 \% \mathrm{Cl}: 1.065,3.067)$, and increased in blood pressure with OR 2.359= (95\%C1: 1.619,3.437).

Figure 2 shows the KAP categorization among the Malays and Orang Asli, while Table 4 shows the KAP score association between ethnicity. For the knowledge category, the majority (67.3\%) of Malays in the good category. In Orang Asli, more than half of them $(51.7 \%)$ them in the poor category, with only $25.8 \%$ of them in the good category. The total mean and standard deviation of knowledge score was $22.28 \pm 6.072$, with a median of 27 and interquartile range (IQR) of 7 for the Malays. Whereas, for the Orang Asli, their knowledge score was significantly less than Malay with mean $12.82 \pm 9.671$, median 13 , and IQR of 19 $(p<0.001)$.

For Malay, the total mean attitude score was $65.52 \pm 5.747$, with a median of 68 and IQR of 7 , which is significantly higher than the Orang Asli with mean attitude score was $59.81 \pm 6.237$ and a median of 60 and IQR of $8(P<0.001)$. However, even though the Orang Asli attitude score lowered than Malays, most of them were in a good attitude category.

For Malays and Orang Asli, only $22.3 \%$ and $16.0 \%$ had a good practice, respectively. The total mean practice score was $7.84 \pm 2.137$, with a median of 8 and IQR 3 for Malays and $7.84 \pm 2.137$, median 8, IQR 2 for Orang Asli with no significant difference among them.

Table 1: Distribution of socio-demographic characteristics $(n=634)$

\begin{tabular}{lcccc}
\hline Characteristics & $\begin{array}{c}\text { Total } \\
\text { no. }(\%)\end{array}$ & $\begin{array}{c}\text { Malay }(\mathbf{n}=309) \\
\text { no. }(\%)\end{array}$ & $\begin{array}{c}\text { Orang Asli }(\mathbf{n}=325) \\
\text { no. }(\%)\end{array}$ & P-value \\
\hline $\begin{array}{l}\text { Socio-demographic } \\
\text { Age category }\end{array}$ & & & & \\
$\quad \begin{array}{l}\text { 18-39 } \\
40 \text { and above }\end{array}$ & $242(38.2)$ & $66(21.4)$ & $176(54.2)$ & - \\
Gender & $392(61.8)$ & $243(78.6)$ & $149(45.8)$ & \\
$\quad$ Male & $225(35.5)$ & $131(42.4)$ & $94(28.9)$ & - \\
$\quad$ Female & $409(64.5)$ & $178(57.6)$ & $231(71.1)$ & \\
Education & & & & \\
$\quad$ None & $123(19.4)$ & $16(5.2)$ & $107(32.9)$ & $<0.001^{* \mathrm{~b}}$ \\
$\quad \begin{array}{l}\text { Primary } \\
\text { Secondary }\end{array}$ & $226(35.6)$ & $101(32.7)$ & $125(38.5)$ & \\
$\quad 233(36.8)$ & $153(49.5)$ & $80(24.6)$ & \\
$\quad$ Tertiary & $50(7.9)$ & $37(12.0)$ & $13(4.0)$ & \\
$\quad$ Others & $2(0.3)$ & $2(0.6)$ & 0 & \\
\hline
\end{tabular}

a Fisher-Exact Test; * Significant at $p<0.05$ levels 
Table 2: Bivariate analysis of disease profile and NCDs risk in Malay $(n=309)$ and Orang Asli $(n=325)$ communities

\begin{tabular}{|c|c|c|c|c|}
\hline Characteristics & $\begin{array}{l}\text { Total, } \\
\text { no. (\%) }\end{array}$ & $\begin{array}{l}\text { Malay, } \\
\text { no.(\%) }\end{array}$ & $\begin{array}{c}\text { Orang Asli, } \\
\text { no. (\%) }\end{array}$ & P-value \\
\hline \multicolumn{5}{|l|}{ Self-reported NCDs } \\
\hline Hypertension & $156(24.6)$ & $108(35.0)$ & $48(14.8)$ & $<0.001^{* a}$ \\
\hline Hypercholesterolemia & $113(17.8)$ & $96(31.1)$ & $17(5.2)$ & $<0.001^{* a}$ \\
\hline Diabetes Mellitus Type II & $64(10.1)$ & $50(16.2)$ & $14(4.3)$ & $<0.001^{* a}$ \\
\hline \multicolumn{5}{|l|}{ NCDs risk } \\
\hline BMI Obese $\left(\geqq 25.00 \mathrm{~kg} / \mathrm{m}^{2}\right)$ & $379(59.3)$ & $184(59.5)$ & $192(59.1)$ & $0.904^{\mathrm{a}}$ \\
\hline Abdominal obesity & $412(65.0)$ & $218(70.6)$ & $194(59.7)$ & $0.004^{* a}$ \\
\hline Increased blood pressure & $265(41.8)$ & $168(54.4)$ & $97(29.8)$ & $<0.001^{* a}$ \\
\hline Increased blood glucose & $45(7.1)$ & $27(8.7)$ & $18(5.5)$ & $0.117^{\mathrm{a}}$ \\
\hline Alcohol consumption & $23(3.6)$ & 0 & $23(7.1)$ & $<0.001^{* a}$ \\
\hline Cigarette Smoker & $189(29.8)$ & $98(31.7)$ & $91(28.0)$ & $0.307^{\mathrm{a}}$ \\
\hline Physically inactive & $330(52.1)$ & $166(53.7)$ & $164(50.5)$ & $0.411^{\mathrm{a}}$ \\
\hline
\end{tabular}

Table 3: Univariate and multivariate analysis of major NCDs and NCDs risk in Malay and Orang Asli communities $(n=634)$

\begin{tabular}{|c|c|c|c|c|}
\hline Variables & $\begin{array}{r}\text { Crude OR } \\
(95 \% \mathrm{Cl})\end{array}$ & P-value ${ }^{b}$ & $\begin{array}{r}\text { Adjusted OR } \\
(95 \% \mathrm{Cl})\end{array}$ & P-value $^{b}$ \\
\hline Hypertension & $3.101(2.109,4.559)$ & $<0.001^{*}$ & $1.038(0.624,1.727)$ & 0.860 \\
\hline Hypercholesterolemia & $8.166(4.737,14.076)$ & $<0.001^{*}$ & $6.035(3.150,11.561)$ & $<0.001^{*}$ \\
\hline Diabetes Mellitus Type II & $4.288(2.318,7.93)$ & $<0.001^{*}$ & $1.760(0.776,3.991)$ & 0.176 \\
\hline BMI Obese $\left(\geqq 25.00 \mathrm{~kg} / \mathrm{m}^{2}\right)$ & $1.020(0.743,1.400)$ & 0.904 & - & - \\
\hline Abdominal obese & $1.618(1.163,2.250)$ & $0.004^{*}$ & $1.807(1.065,3.067)$ & $0.025^{*}$ \\
\hline Increased blood pressure & $2.801(2.021,3.88)$ & $<0.001^{*}$ & $2.359(1.619,3.437)$ & $<0.001^{*}$ \\
\hline Increased blood glucose & $0.612(0.330,1.136)$ & 0.120 & $0.681(0.315,1.469)$ & 0.327 \\
\hline Cigarette Smoker & $1.194(0.850,1.679)$ & 0.307 & - & - \\
\hline Physically inactive & $1.140(0.834,1.557)$ & 0.412 & & - \\
\hline
\end{tabular}

asimple logistic regression, ${ }^{b}$ Multiple logistic regression; Minimum tolerance value $=0.587 ;$ Maximum VIF value= 1.702; Hosmer-Lemeshow test $P$-value= 0.508; Overall percentage correct=67.4\%; Dependent variables: Malay ethnicity

Table 4: Association between ethnicity with total scores of knowledge, attitude, and practice regarding NCDs using Mann-Whitey Test $(n=634)$

\begin{tabular}{lccccc}
\hline \multirow{2}{*}{ Characteristics } & \multicolumn{2}{c}{ Malay $(\mathbf{n}=\mathbf{3 0 9})$} & \multicolumn{2}{c}{ Orang Asli $(\mathbf{n}=\mathbf{3 2 5})$} & P-value \\
\cline { 2 - 5 } & mean (SD) & median (IQR) & mean $(\mathrm{SD})$ & median (IQR) & \\
\hline Knowledge & $22.28(6.072)$ & $27(7)$ & $12.82(9.671)$ & $13(19)$ & $<0.001^{*}$ \\
Attitude & $65.52(5.747)$ & $68(7)$ & $59.81(6.237)$ & $60(8)$ & $<0.001^{*}$ \\
Practices & $7.84(2.137)$ & $8(3)$ & $7.66(1.780)$ & $8(2)$ & 0.800
\end{tabular}




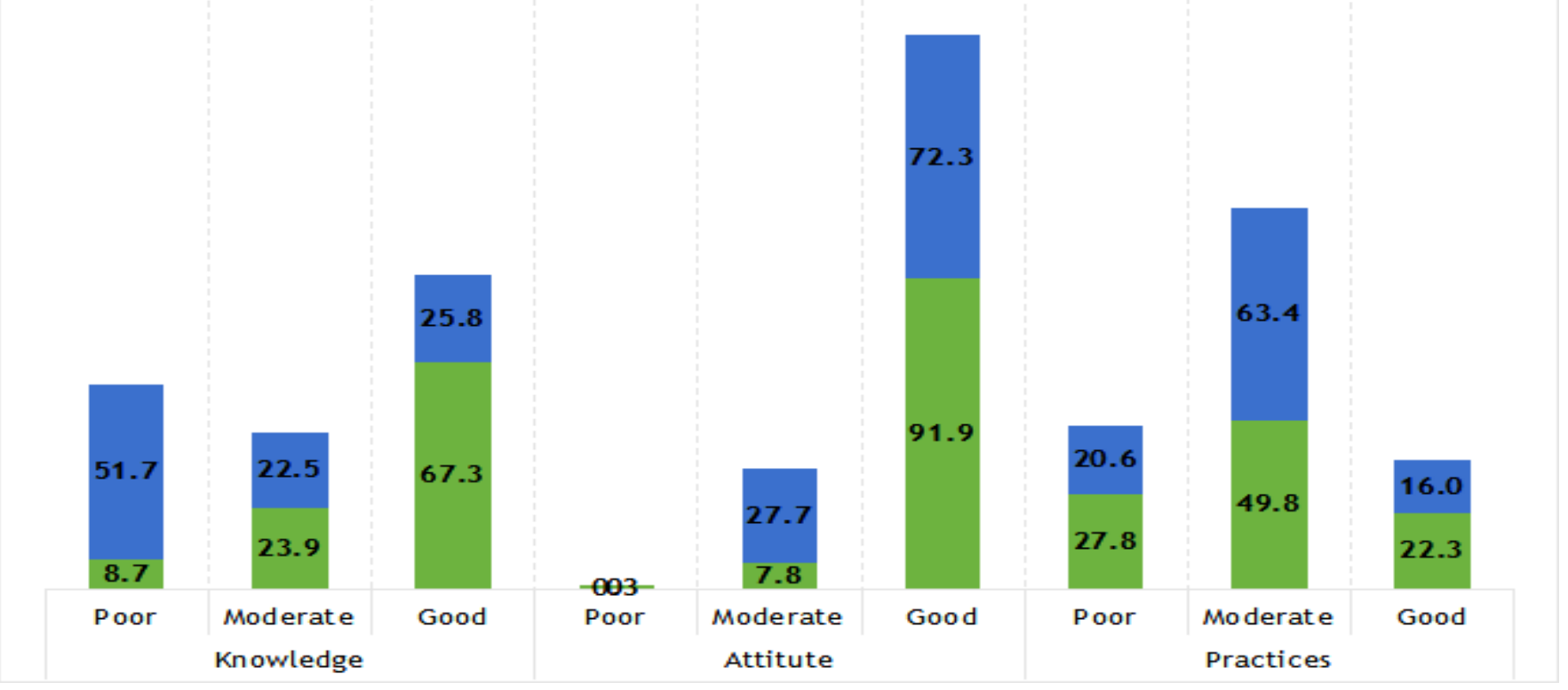

Figure 1: Level of knowledge, attitude and practices among respondents by percentages

\section{DISCUSSION}

The study found that the overall prevalence of NCDs among the rural population for hypertension, hypercholesterolemia, and diabetes mellitus was $24.6 \%, 17.8 \%$, and $10.1 \%$, respectively. The rate was higher compared to the national report by Institute for Public Health for Malaysian rural populations, which were $12.8 \%$, 7.1\%, and 7.2\% for hypertension, hypercholesterolemia, and diabetes mellitus, respectively ${ }^{3}$. The rates of NCDs may vary in different populations based on their demographic profiles, lifestyles, and on the diet and food intake. Negeri Sembilan is among the highest state-reported with this NCDs condition, with most of the participants in this study aged above 40 years old, thus contributed to the reported rate in this study slightly higher compared to general Malaysian populations $3,26,27$. For the transitional community living in the rural, epidemiological transition towards modernization lead to a similar prevalence of NCDs trend comparable to the urban population ${ }^{28}$.

An earlier study in Perak rural community also reported a similar finding, which showed the Malays had a higher prevalence of metabolic syndrome conditions and cardiovascular risk factors as compared to the Orang Asli ${ }^{6,7}$. However, these studies also emphasize the increased prevalence of this NCDs risk as compared to very early reported studies among Orang Asli with lowrisk factors and the absence of coronary heart disease ${ }^{29}$ and prevalence of diabetes mellitus was $0.3 \%$ back in $1993^{30}$. The Orang Asli tribe in this study was from the Temuan subtribe. Comparing to another study among Proto-Malays from the Jakun tribe reported a lower prevalence of diagnosed hypertension, hypercholesterolemia, and diabetes with a prevalence of $9.7 \%, 0$, and $4.2 \%$, respectively ${ }^{31}$.

During these early studies also found that none of the Orang Asli was obese. However, we found no significant difference in BMI obese in these communities, with more than half of the respondents, were having a BMI obese ${ }^{29}$. Abdominal obesity among Malays was significantly higher, but the percentages were also high among Orang Asli as compared to the study reported by Ali et al.in 2016 ${ }^{7}$. The rural community of Malays and Orang Asli with a high prevalence of BMI obese (59.3\%) and abdominal obesity (65.0\%), which indicates that either they had a sedentary lifestyle or an unbalanced diet ${ }^{31,32}$. In this study, the participants with increased blood pressure and blood glucose were also worrying. Even though the percentage among the Orang Asli was lower compared to Malays, the percentages were also higher than reported by Wong et al.in 2018 in the Orang Asli ${ }^{31}$

The social behaviour in terms of alcohol drinking habits, smoking, and physical activity may determine the distribution of disease in both communities. Harmful use of alcohol is known to cause cardiovascular diseases, diabetes, and cancers ${ }^{9}$. Since alcohol is prohibited among Muslim Malay, none of them were alcohol drinkers. 
The four main types of NCDs contributed to modifiable behaviour risk factors of tobacco used $^{9}$. No significant difference found for smoking in both communities. Even though the Orang Asli reported lower percentages of smokers compared to the Malays, previous studies reported that among those who smoked, the percentage of heavy smokers was higher among the Orang Asli compared to Malays ${ }^{32}$. Since this study did not explore the pattern of the cigarette or tobacco smoking, further studies to gather this data may be essential as behaviour is modifiable. Additional to that, a study on smoking behaviour among secondary school students in Negeri Sembilan also showed a worrying trend with rural adolescents (15.3\%) had significantly higher percentages of current smokers compared to $12.8 \%$ of urban adolescents. The prevalence of smoking was also higher among Malay (20.4\%) and Orang Asli (17.0\%) adolescents ${ }^{33}$. This problem should be curbed early as this behaviour will last until their adulthood if no preventive and health promotion strategic that lead to additional public health burden to the government.

The physical activity is known as a protective factor from the development of cardiovascular diseases and diabetes ${ }^{34}$. However, about half of the respondents were physically inactive with no significant difference in both communities. Environmental plays an essential role in the involvement of physical activity. Even for the rural indigenous community locally and worldwide, lack of physical activity was observed due to poor maintenance of natural resources and limited access to space and facilities that support an active lifestyle in their settlement, which has implications for NCDs risk later in life $\mathrm{e}^{35,36}$.

In this study also, only $24.6 \%$ of the Orang Asli completed secondary school, which was less than half the national average of $72.0 \%{ }^{37}$. The low educational attainment among the Orang Asli posed a severe limitation for acquiring knowledge on health-related disease, including NCDs. Finding from this study shows poor knowledge on the NCDs in the Orang Asli compared to rural Malays. This knowledge disparities among the Orang Asli in Malaysia have been previously reported even in the more urbanized Orang Asli $38-40$. With a low attitude towards disease, it might pose an additional challenge for the government in disease management in this vulnerable population as chronic diseases may develop slowly without early signs and symptoms of illness until later stages. For NCDs management within the primary health care system provided by Malaysian government is on integrated and comprehensive service delivery at the first point of contact to provide a full range of NCDs services, including: promotive, preventive or wellness services; screening; identification of risk factors; intervention; treatment; and rehabilitation ${ }^{41}$.
Finding from this study shows low lifestyle practices behaviour with no significant difference in both communities. Therefore, preventive strategies that aimed at reducing exposure to the risk of diseases including early risk identification through screening, risk intervention via increasing education and health promotion, and risk management of continuous disease monitoring shall be strategic in both communities, particularly among the Orang Asli.

For the Orang Asli, numbers of research consistently show the link between their lifestyle changes and obesity, metabolic syndrome, and ultimately $\mathrm{NCDs}^{7,31,40}$. Due to the vulnerability of this community and the heterogeneity across tribe, the differences in disease burden and risk factors that affect groups of Indigenous people shall be explored further as it is known that large numbers of people's in this community with low income, lagging in education and poor living conditions ${ }^{42}$. The use of mix methods as the basis for exploring this issue using the quantitative and qualitative approach suggested in the future. In community practices, the input gathers from this approach will provide more meaningful data for a targeted intervention program that suits to the community can be designed ${ }^{31,43}$.

This cross-sectional study could not determine the cause-effect relationship, and the findings from this study could not be generalized to the rest of the rural communities, particularly among Orang Asli populations in Malaysia due to their heterogeneous across tribe ${ }^{42}$. The degree of generalizability also remains a potential issue associated as a convenience method used for sampling methods. However, this method was commonly used mainly in the study among the Orang Asli populations ${ }^{13,44}$. There was a likelihood of data misreporting due to the respondents either under- or over-reporting for their prevalence of the diseases. Nevertheless, to the best of our knowledge, this was the first study that attempted to assess the knowledge, attitude, and knowledge of lifestyle behaviour risk NCDs as previous studies more focus on a specific type of NCDs in rural Malaysian and also among the Orang Asli in Malaysia. This study also determined the burden of major NCDs and their NCDs risk factors among transitional communities that living with one another.

\section{CONCLUSION}

Life-style related NCDs is at an alarming level in a rural community with an increasing burden among the Orang Asli communities. With lower knowledge and attitude on the diseases and comparable in terms of life-style behavioural practices level among the Orang Asli, immediate actions by researcher, health professional and also government agencies is essential to educate the people at risk so further early screening and prevention of health risks can be strategic since 
this life-style related NCDs is modifiable and preventable.

\section{Financial Sponsorship:}

USIM / BANKRAKYAT_K1 / FPSK / 052002/42117 Grant under the Mizan Research Center, Universiti Sains Islam Malaysia, Malaysia.

\section{Conflict of Interest}

There is no conflict of interest with regard to the study.

\section{ACKNOWLEDGEMENT}

Authors would like to thank the Health Department of Jelebu, The Department of Orang Asli Development (JAKOA), Village Community Management Council (MPKK), and Komuniti Sihat Perkasa Negara (KOSPEN) which contributed their time and energy. We want to acknowledge the Director-General of Health Malaysia for the permission granted to publish this article.

\section{REFERENCES}

1. World Health Organization. Noncommunicable diseases country profiles 2018. Geneva, Switzerland: World Health Organization 2018.

2. World Health Organization. Noncommunicable diseases: the slow-motion disaster. Geneva, Switzerland: World Health Organization 2017.

3. Institute for Public Health (IPH). National Health and Morbidity Survey 2015 (NHMS) Vol. II: NonCommunicable Diseases, Risk Factors \& Other Health Problems. Kuala Lumpur: Ministry of Health Malaysia 2015.

4. Phua KL. The health of Malaysia's "Orang Asli" peoples: A review of the scientific evidence on nutritional outcome, parasite infestations, and discussion on implications for clinical practice. Malaysian Journal of Public Health Medicine. 2015;15(1):83-90.

5. Adrian Jinam $T$, Elvira Phipps $M$, Indran M, Rani Kuppusamy U, Ameen Mahmood A, Hong LC, et al. An update of the general health status in the indigenous populations of Malaysia. Ethn Health. 2008;13(3):277-87.

6. Ali $O$, Ismail $S$, Sugathan $S$, Soe $M M$, Ahmed W, Hayati A, et al. Determination of metabolic syndrome (MetS) among transitional community-comparison between Orang Asli and Malay rural area in
Perak. 7th RRPG International Conference and Field Study in Malaysia 2016; UTM Skudai, Johor Bahru, Malaysia. p. 429-33.

7. Ahmad W, Sugathan S, Ismail S, Soe MM, Ali O. Cardiovascular risk factors in rural Malays and Aborigines in Perak, Malaysia; an alarming situation. Medical Forum Monthly. 2018;29(12):24-8.

8. Loef $M$, Walach $\mathrm{H}$. The combined effects of healthy lifestyle behaviors on all-cause mortality: A systematic review and meta-analysis. Prev Med. 2012;55(3):163-70.

9. Forouzanfar $\mathrm{MH}$, Afshin A, Alexander LT, Anderson HR, Bhutta ZA, Biryukov $S$, et al. Global, regional, and national comparative risk assessment of 79 behavioural, environmental and occupational, and metabolic risks or clusters of risks, 1990-2015: a systematic analysis for the Global Burden of Disease Study 2015. Lancet. 2016;388(10053):1659-724.

10. Abdul-Razak S, Daher AM, Ramli AS, Ariffin F, Mazapuspavina MY, Ambigga $\mathrm{KS}$, et al. Prevalence, awareness, treatment, control and socio demographic determinants of hypertension in Malaysian adults. BMC Public Health. 2016;16(1):351.

11. Buang NFB, Rahman NAA, Haque M. Knowledge, attitude and practice regarding hypertension among residents in a housing area in Selangor, Malaysia. Med Pharm Rep. 2019;92(2):145-52.

12. Ithnin $M$, Nor NAUM, Juliana $N$, Effendy NM, Sahar MA, Abdullah KHA, et al. Knowledge, attitude, and practice on Non-Communicable Diseases (NCDs) among the adult population in the urban area of Negeri Sembilan, Malaysia. International Journal of Research in Pharmaceutical Sciences. 2018;9(SPL 2):88-94.

13. Ahmad B, Khalid B, Quek K, Zaini A, Phipps ME. Knowledge of diabetes and lifestyle behaviour amongst indigenous population in Peninsular Malaysia. Medical Journal of Malaysia. 2013;68(4):309.

14. World Medical Association. World Medical Association Declaration of Helsinki. Ethical principles for medical research involving human 
subjects. Bull World Health Organ. 2001;79(4):373-4.

15. Lwanga SK, Lemeshow S. Sample size determination in health studies: a practical manual. Geneva: World Health Organization; 1991.

16. Kalton G. Systematic Sampling. In: N. Balakrishnan TC, B. Everitt, W. Piegorsch, F. Ruggeri and J.L. Teugels, editor. Wiley StatsRef: Statistics Reference Online. New Jersey: John Wiley \& Sons, Ltd.; 2017. p. 1-6.

17. George D, Mallery M. Using SPSS for Windows step by step: a simple guide and reference. Boston, MA: Allyn \& Bacon; 2003.

18. World Health Organization (WHO). Global recommendations on physical activity for health. Geneva, Switzerland: World Health Organization 2010.

19. Chan YY, Teh CH, Lim KK, Lim KH, Yeo PS, Kee CC, et al. Lifestyle, chronic diseases and self-rated health among Malaysian adults: results from the 2011 National Health and Morbidity Survey (NHMS). BMC Public Health. 2015;15(1):754.

20. World Health Organization, Western Pacific Regional Office, International Association for the Study of Obesity, International Obesity Task Force. The Asia-Pacific perspective: Redefining obesity and its treatment. Melbourne, Australia: Health Communications Australia 2000.

21. Janssen I, Katzmarzyk PT, Ross R. Body Mass Index, Waist Circumference, and Health Risk: Evidence in Support of Current National Institutes of Health Guidelines. Archives of Internal Medicine. 2002;162(18):2074-9.

22. Myers J. Exercise and Cardiovascular Health.Circulation. 2003;107(1):e2e5.

23. Imai $Y$, Otsuka K, Kawano $Y$, Shimada $\mathrm{K}$, Hayashi $\mathrm{H}$, Tochikubo $\mathrm{O}$, et al. Japanese Society of Hypertension (JSH) Guidelines for Self-Monitoring of Blood Pressure at Home. Hypertension Research. 2003;26(10):771-82.

24. Chan YH. Biostatistics 201: linear regression analysis. Singapore Medical Journal. 2004;45(2):55-61.
25. Thayer JD. Stepwise Regression as an Exploratory Data Analysis Procedure. Annual Meeting of the American Educational Research Association; 2002 1-5 April 2002; New Orleans, LA.

26. Suriah A, Zainorni $M$, Shafawi $S$, Suraya M, Zarina N, WA WZ, et al. Nutrient intake among elderly in southern Peninsular Malaysia. Malays J Nutr. 1996;2(1):11-9.

27. Tan K. Factors influencing physical inactivity among adults in Negeri Sembilan, Peninsular Malaysia. Med J Malays. 2019;74(5):389-93.

28. Seong AC, John CKM. A review of coronary artery disease research in Malaysia. Med J Malays 2016;71:4257.

29. Burns-Cox C, Chong Y, Gillman R. Risk factors and the absence of coronary heart disease in aborigines in West Malaysia. British Heart Journal. 1972;34(9):953.

30. Ali O, Tan T, Sakinah O, Khalid B, Wu $\mathrm{LL}, \mathrm{Ng}$ M. Prevalence of NIDDM and impaired glucose tolerance in aborigines and Malays in Malaysia and their relationship to sociodemographic, health, and nutritional factors. Diabetes Care. 1993;16(1):68-75.

31. Wong C, Faiz D, Safraa SD, Azim RRM, Zubaidah AS. Prevalence and Modifiable Risk Factors of NonCommunicable Diseases among Jakun Orang Asli at Tasik Chini, Pekan, Pahang. International Medical Journal of Malaysia. 2018;17(3):3-16.

32. Ali O, Shamsuddin Z, Khalid B. Socioeconomic, social behaviour and dietary patterns among Malaysian aborigines and rural native Malays. Med J Malays. 1991;46(3):222-9.

33. Lee LK, Paul CYC, Kam CW, Jagmohni K. Smoking among Secondary School Students in Negeri Sembilan, Malaysia. Asia Pac J Public Health. 2005;17(2):130-6.

34. Teh CH, Chan YY, Lim KH, Kee CC, Lim $\mathrm{KK}$, Yeo PS, et al. Association of physical activity with blood pressure and blood glucose among Malaysian adults: a population-based study. BMC Public Health. 2015;15(1):1205.

35. Saimon R, Choo WY, Chang KH, Ng CJ, Bulgiba A. Physical Activity Among Adolescents in an East Malaysian Rural Indigenous Community:Exploring the 
Influence of Neighborhood Environmental Factors. Asia Pac J Public Health. 2015;27(8_suppl):33S$40 \mathrm{~S}$.

36. Yeates K, Lohfeld L, Sleeth J, Morales F, Rajkotia Y, Ogedegbe O. A global perspective on cardiovascular disease in vulnerable populations. Can J Cardiol. 2015;31(9):1081-93.

37. Ministry of Education. Malaysian Education Blueprint 2013-2025. Putrajaya, Malaysia: Ministry of Education 2013.

38. Haemamalar K, Zalilah MS, Neng Azhanie A. Nutritional Status of Orang Asli (Che Wong Tribe) Adults in Krau Wildlife Reserve, Pahang. Malays J Nutr. 2010;16(1):55-68.

39. Ahmad B, Khalid B, Quek K, Zaini A, Phipps ME. Knowledge of diabetes and lifestyle behaviour amongst indigenous population in Peninsular Malaysia. Med J Malays. 2013;68(4):309.

40. Nasr NA, Al-Mekhlafi HM, Ahmed A, Roslan MA, Bulgiba A. Towards an effective control programme of soil- transmitted helminth infections among Orang Asli in rural Malaysia. Part 2: Knowledge, attitude, and practices. Parasit Vectors. 2013;6(1):28

41. Mustapha FI, Omar ZA, Mihat O, Md Noh K, Hassan N, Abu Bakar R, et al. Addressing non-communicable diseases in Malaysia: an integrative process of systems and community. BMC Public Health. 2014;14(2): S4.

42. Masron T, Masami F, Ismail N. Orang Asli in Peninsular Malaysia: population, spatial distribution and socio-economic condition. Ritsumeikan Soc Sci Humanit. 2013;6:75-115.

43. Denscombe $M$. Communities of practice: A research paradigm for the mixed methods approach. J Mix Methods Res. 2008;2(3):270-83.

44. Yusof HM, Ching TS, Ibrahim R, Lola S. Anthropometric indices and life style practices of the indigenous Orang Asli adults in Lembah Belum, Grik of Peninsular Malaysia. Asia Pac J Clin Nutr. 2007;16(1):49-55. 